\title{
Liquid Biopsy of Hepatocellular Carcinoma: Circulating Tumor-Derived Biomarkers
}

\author{
Chang-Qing Yin, ${ }^{1}$ Chun-Hui Yuan, ${ }^{2}$ Zhen Qu, ${ }^{2}$ Qing Guan, \\ Hao Chen, ${ }^{1}$ and Fu-Bing Wang ${ }^{1}$ \\ ${ }^{1}$ Department of Laboratory Medicine and Center for Gene Diagnosis, Zhongnan Hospital of Wuhan University, \\ No. 169 Donghu Road, Wuchang District, Wuhan 430071, China \\ ${ }^{2}$ Department of Immunology, School of Basic Medical Sciences, Wuhan University, No. 185 Donghu Road, Wuchang District, \\ Wuhan 430071, China
}

Correspondence should be addressed to Fu-Bing Wang; wfb20042002@sina.com

Received 16 March 2016; Revised 6 May 2016; Accepted 15 May 2016

Academic Editor: Michele Malaguarnera

Copyright (C) 2016 Chang-Qing Yin et al. This is an open access article distributed under the Creative Commons Attribution License, which permits unrestricted use, distribution, and reproduction in any medium, provided the original work is properly cited.

\begin{abstract}
Hepatocellular carcinoma (HCC) is the second leading cause of cancer-related death worldwide due to latent liver disease, late diagnosis, and nonresponse to systemic treatments. Till now, surgical and/or biopsy specimens are still generally used as a gold standard by the clinicians for clinical decision-making. However, apart from their invasive characteristics, tumor biopsy only mirrors a single spot of the tumor, failing to reflect current cancer dynamics and progression. Therefore, it is imperative to develop new diagnostic strategies with significant effectiveness and reliability to monitor high-risk populations and detect HCC at an early stage. In the past decade, the potent utilities of "liquid biopsy" have attracted intense concern and were developed to evaluate cancer progression in several clinical trials. "Liquid biopsies" represent a series of noninvasive tests that detect cancer byproducts easily accessible in peripheral blood, mainly including circulating tumor cells (CTCs) and cell-free nucleic acids (cfNAs) that are shed into the blood from the tumor sites. In this review, we focus on the recent developments in the field of "liquid biopsy" as well as the diagnostic and prognostic significance of CTCs and cfNAs in HCC patients.
\end{abstract}

\section{Introduction}

Hepatocellular carcinoma (HCC) is the sixth most common cancer worldwide (782,451 cases in $2012,5.6 \%$ of all cancers); however, it ranks as the second cause of cancer-related death (nearly 745,553 deaths in 2012, 9.1\% of all cancers) [1, 2]. Owing to the characters of hepatocellular carcinoma, like insidious onset, high degree of malignancy, and nonspecific symptoms in early stage, the prognosis of HCC remains dismal with a 5 -year overall survival rate of $0 \%-10 \%$ [3-5]. Conventional diagnostic methods for the detection of HCC include serological tests and imaging examination, however, which show less sensitivity and specificity, and most patients diagnosed with HCC are already in advanced stage or with underlying liver diseases [6]. Traditional computed tomography (CT) scan, for example, can be used to detect changes in tumor size but does not provide information regarding the biology of the tumor. Additionally, CT scan is typically examined in an interval of several months because it is not sensitive enough to detect minimal tumor volume changes in short period. Serological tests include $\alpha$-fetoprotein (AFP), descarboxy prothrombin (DCP), and AFP-L3, which have been studied alone or in combination [7]. However, available data has shown that the elevation of such serum tumor markers is only weakly associated with the tumor progression and may be elevated for tumor-uncorrelated reasons. For example, AFP is the widely used molecular markers for clinical HCC diagnosis; however, it often showed a falsepositive result during pregnancy, as well as active liver disease, embryonic tumor, and certain gastrointestinal tumors [79]. Therefore, to facilitate the development of "precision medicine" cancer management program, the importance 


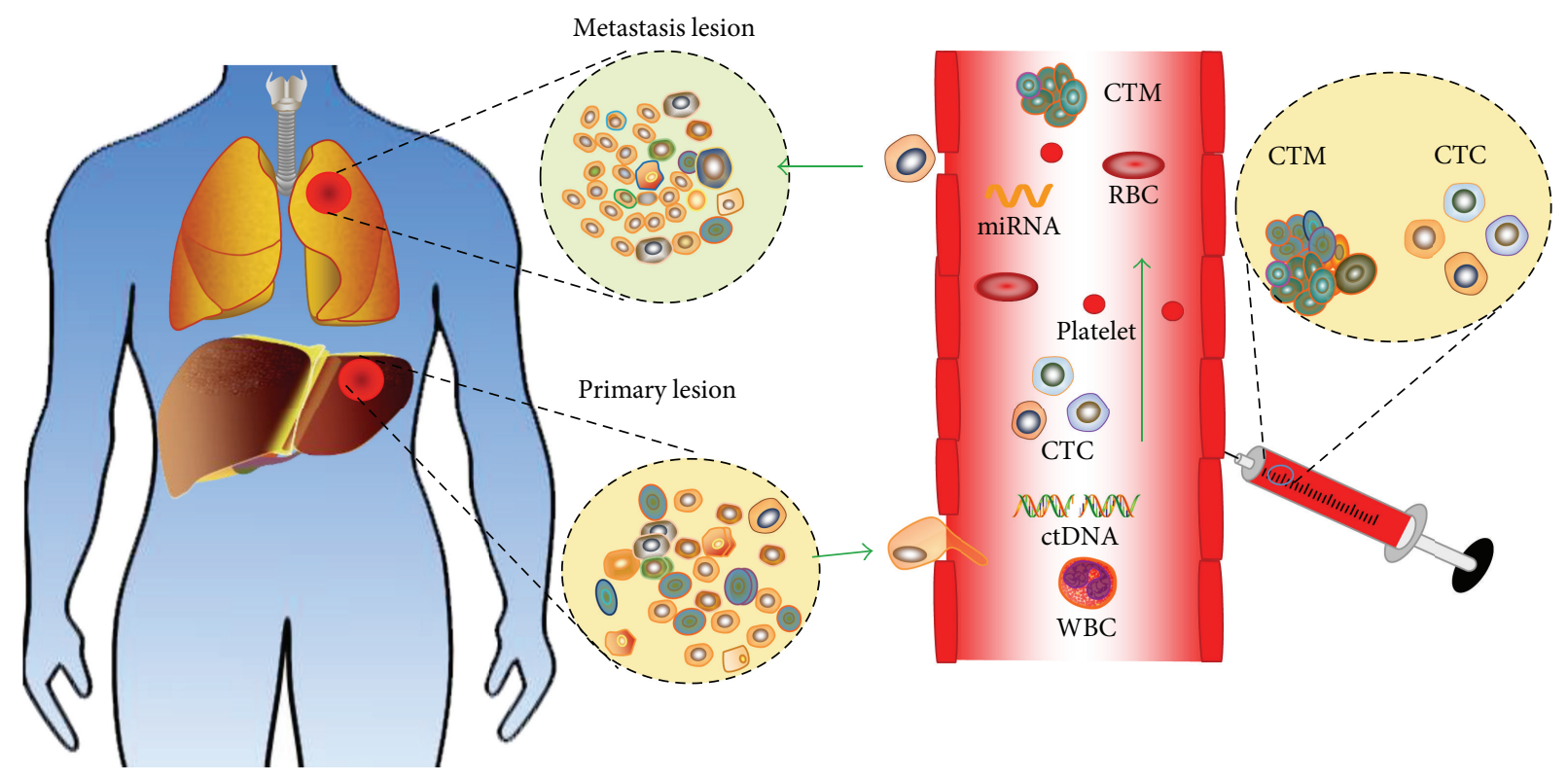

FIGURE 1: Liquid biopsy of hepatocellular carcinoma: circulating tumor cells (CTCs) and cell-free tumor-associated DNA or miRNAs (cfNAs) are easily accessible in peripheral blood of patients. Analysis of these cells or molecules can be used for early tumor detection and provide prognostic information for HCC patients.

of developing useful diagnostic and monitoring tools that provide timely and accurate information for an individual cancer patient should be emphasized.

In the past few decades, numerous studies have demonstrated the potent utility of circulating cancer byproducts detection (e.g., CTCs, cfNAs), namely, "liquid biopsy," which could provide accessible, accurate, and dynamic information to evaluate tumor progression (Figure 1). Unlike a traditional biopsy, several advantages seem to contribute to the prevalence of "liquid biopsy": (1) it is a noninvasive procedure that can be conducted routinely without any clinical difficulties; (2) it allows us to have repeated samplings which offer a multifaceted portrait of the disease over time, whereas tissue samples only give doctors a localized picture; (3) it is more likely to capture the overall genetic complexity of both primary and metastatic lesions in patients with advanced disease; and (4) it is much faster and cheaper than classical biopsy testing for early disease detection $[10,11]$.

Therefore, with the aim of gaining a better insight into the "liquid biopsy" in patients with HCC, we provide a comprehensive overview of the historical backgrounds, characterizations, and recent developments of both CTCs and cfNAs in patients with HCC and discuss future perspectives.

\section{Circulating Tumor Cells (CTCs)}

Circulating tumor cells are widely recognized as the "seeds" of tumors, which are shed into peripheral blood from carcinoma in situ and eventually establish metastatic carcinoma in other organs. The presence of CTCs was observed for the first time in 1869 in the blood of a man with metastatic cancer by Ashworth, who also hypothesized that they would throw some light on the origin of multiple tumors existing in the same person [12]. However, for over a century, CTC research has been hampered by the incapacity to detect these rare cells, which are estimated in frequencies of about 1-10 CTCs in a background of millions of blood cells in patients with metastatic disease [13]. Therefore, the major challenge for CTC researchers is the difficulty in CTC purification which directly determined the following molecular characterization and clinical evaluation of CTCs.

In recent years, many different CTC isolation technologies have emerged to improve CTC isolation or detection rates, and they are mainly categorized into two groups: physical methods and biological methods. The former methods mainly depend on the physical properties of CTCs, such as size, density, electric charge, migratory capacity, and deformability [44]. The biological methods mainly rely on antigen-antibody binding, and antibodies against tumor specific biomarkers including epithelial cell adhesion molecule (EpCAM), human epidermal growth factor receptor 2 (Her2), and prostate-specific antigen (PSA) are usually used in CTCs purification [45]. In particular, EpCAM is the most commonly used antigen in CTCs purification because its expression is virtually universal (albeit at variable levels) in cells of epithelial origin, but it is absent in blood cells [45, 46] and more importantly, up to now, EpCAM-based CellSearch ${ }^{\mathrm{TM}}$ (Veridex LLC, NJ, USA) is still the first and only clinically validated, FDA-approved test for capturing and enumerating CTCs to facilitate clinical decision-making. In this platform, tumor cells are first enriched immunomagnetically by EpCAM antibody-coupled magnetic beads. Subsequently, recovered cells are permeabilized and immunostained with a nuclear stain $\left(4^{\prime}, 6^{\prime}\right.$-diamidino-2-phenylindole hydrochloride; DAPI), a fluorescent antibody conjugate against CD45 (leukocyte marker), and cytokeratin 8 , cytokeratin 18 , and 


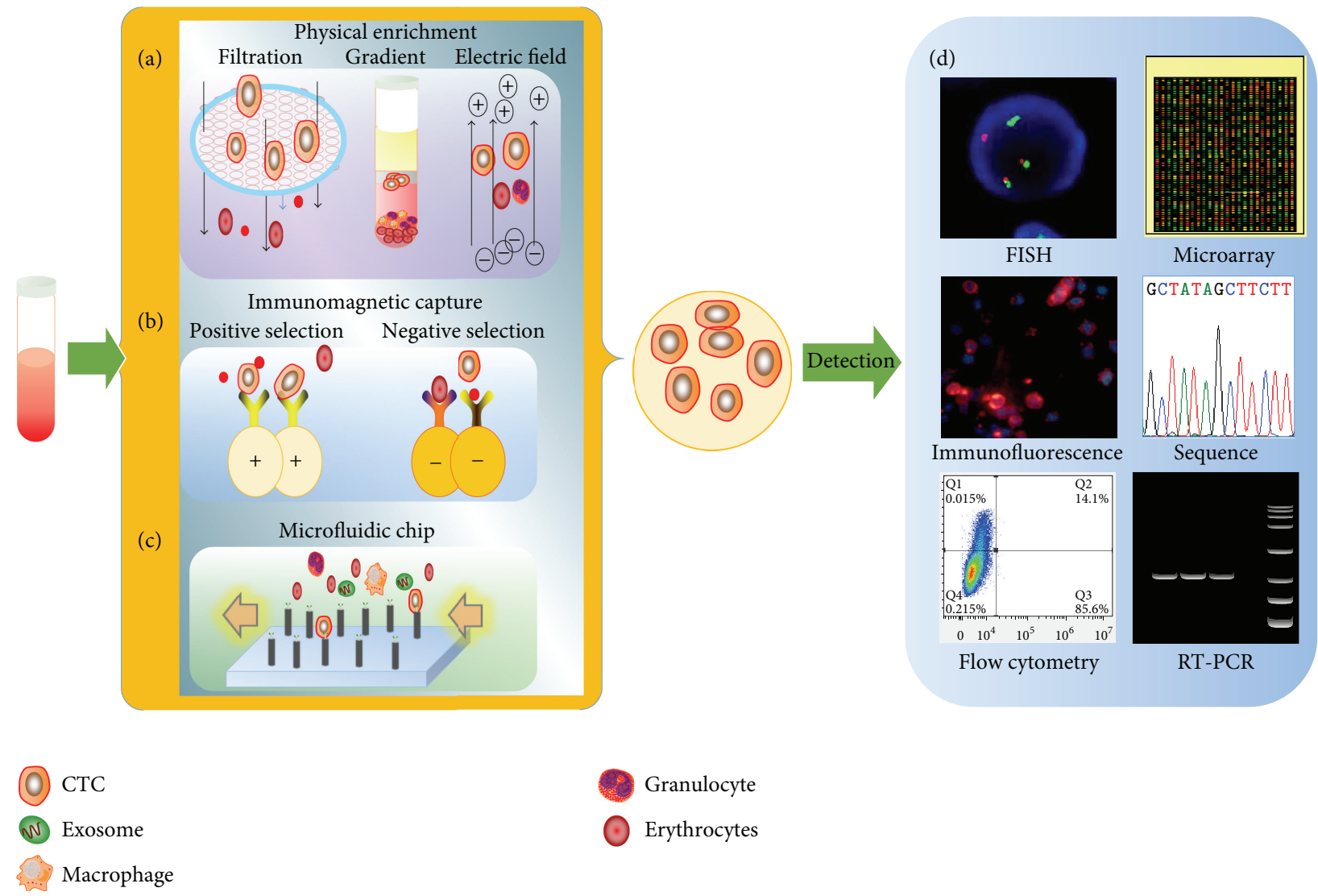

FIgURE 2: Schematic model of CTCs enrichment and further identification of molecular information. Enrichment of CTCs from the peripheral blood of cancer patients is based on the following principles: CTCs can be enriched on the basis of physical properties, including size (filtration-based devices), density (Ficoll centrifugation), and electric charges (dielectrophoresis) (a). CTCs can also be positively or negatively enriched on the basis of the expression of cell surface markers (EpCAM for positive selection and CD45 for negative selection) (b). CTCs can also be trapped from PBMCs by flowing through posts in a microfluidic chip on the basis of both physical and biological properties (c). The subsequent analysis of CTCs including fluorescence in situ hybridization (FISH), microarray, immunofluorescence, sequencing, flow cytometry, and RT-PCR (d).

cytokeratin 19 (cytoplasmic epithelial markers) [47]. However, although immunocapture enrichment methods could acquire high purity of CTCs, such methods may miss the tumor cells with highly metastatic potential due to the epithelial-mesenchymal transition (EMT) process of CTCs, which is characterized by decreased expression of epithelial markers and the acquisition of mesenchymal features [48]. Therefore, alternative enrichment approaches should also take mesenchymal markers into account and avoid the biased capture of CTC population.

Most recently, the microfluidic-based "CTC-chip" has attracted intense attention due to its enhanced sensitivity and specificity in CTCs purification as demonstrated by the accumulated evidence $[49,50]$. In this platform, CTCs could be isolated from small volumes of blood samples by flow through "antibody"-coated microposts. And, compared with macroscale approaches, microfluidic devices offer multiple advantages for CTC isolation including the enhanced interactions between the CTCs and the functionalized surface and dynamic flows that prohibit nonspecific binding [51].
Classifications of current CTC enrichment and detection technologies are presented in Figure 2.

\section{CTCs Detection in HCC Patients and Its Clinical Relevance}

By now, many researchers have tried to detect CTCs in patients with HCC and described their relevance to clinical outcome using various approaches, among which EpCAMbased methods are still the most widely employed $[46,52]$. The area under curve (AUC) for EpCAM ${ }^{\mathrm{mRNA}+}$ CTCs in discrimination between patients with HCC and the others (healthy volunteers, patients with hepatitis B and/or cirrhosis, and patients with benign tumor) was 0.697 , with sensitivity of $42.6 \%$ and specificity of $96.7 \%$. In particular, when combined with AFP level, the diagnostic value of CTCs was significantly improved and the AUC was 0.857 with sensitivity of $73.0 \%$ and specificity of 93.4\% [52]. Besides EpCAM, we have initially carried out the aptamer-based "CTC-chip" to capture CTCs in HCC patients with a satisfactory capture ratio 
$(\sim 61 \%)$ [51]. With regard to other methods, Vona et al. [44] firstly used the isolation by size of epithelial tumor cell (ISET) method in 2004 to detect CTCs in 44 cases of HCC patients and explored their clinical diagnostic value. The study showed that CTCs and circulating tumor microemboli (CTM) were detected in 52\% (23/44) of HCC patients, while, in healthy volunteers, chronic active hepatitis or cirrhosis patients were not detected.

Furthermore, the numbers of CTCs and CTM were also closely correlated with tumor infiltration, portal vein thrombosis, and Child-Pugh class grade B/C level and predicted a poor prognosis of HCC patients [44, 52-57]. EpCAM $^{\text {mRNA+ }}$ CTC was the only independent prognostic factor for time to recurrence (TTR) of HCC patients [52]. Patients with preoperative detectable EpCAM ${ }^{\text {mRNA+ }}$ CTCs had significantly shorter TTR (median, 10.9 months versus not reached) and higher recurrence rates (59.6\% versus 25.7\%) than those without detectable EpCAM ${ }^{\text {mRNA+ }}$ CTCs. Both the presence and number of CTCs and CTM were significantly associated with a shorter survival [44]. Thus, in order to systematically validate the prognostic value of CTCs detection in HCC patients, we have conducted a metaanalysis of twenty-three published studies [58]. The results show that CTCs' positivity was significantly associated with relapse-free survival (RFS) and overall survival (OS), as well as the characteristics of tumor progression, including TNM stage, vascular invasion, and tumor sites of HCC patients. However, large-scale multicentre trials are still needed to substantiate the claim that CTCs detection will contribute to the future clinical management of HCC patients.

\section{Characterization of cfNAs}

Circulating cell-free nucleic acids (cfNAs) in peripheral blood of cancer patients comprise DNA, mRNA, and miRNAs [59-61]. The earliest report of cfNAs in human peripheral blood was in 1948 [62]; however, cfNAs did not gain attention until 1994, about 50 years later, when studies identified that cfNAs could reflect the RAS gene mutations of cancer patients and thus serve as a kind of tumor markers $[63,64]$.

\section{Circulating Cell-Free DNA (cfDNA)}

Normal cells can actively secrete nucleic acids to the peripheral blood in the physiological state, cfDNA in the presence of normal human peripheral blood at an average concentration of $30 \mathrm{ng} / \mathrm{mL}(0-100 \mathrm{ng} / \mathrm{mL})$ [65]. The content of cfDNA in peripheral blood is equivalent to 5000 genomes [66], as a genomic DNA content was approximately $6.6 \mathrm{pg}[67,68]$; thus, the peripheral blood is like a "liquid biopsy samples library" which contains large amounts of genetic information. Normal tumor cells and apoptotic and necrotic tumor cells in the tumor microenvironment are considered to be the major source of tumor-related cfDNA in blood of cancer patients [5, 69]. Apoptotic and necrotic tumor cells are usually phagocytized by macrophages or other scavenger cells which can release digested DNA into the circulating system [70]. Compared with healthy subjects, HCC patients contained large amount of tumor-related cfDNAs which are not affected by the size of the tumor and only associated with the degree of malignancy [71], and the amount of circulating DNA is negatively associated with the 3 -year DFS and OS of HCC patients [72].

cfDNA is mainly metabolized by the liver, spleen, and kidney $[5,73]$, and its half-life is just about $4 \mathrm{~min}$ to several hours. Therefore, the dynamic level of tumor-related cfDNA reflects the average state of the tumor genome molecular features, which include mutations, copy number variation, methylation abnormalities, microsatellite instability, and loss of heterozygosity, in peripheral blood of cancer patients [74, 75]. Qualitative and quantitative analysis of these changes will help to assess the biological characteristics of the tumor.

\section{Detection of cfDNA Mutation and Copy Number Variation in Peripheral Blood}

Detection of specific gene mutation in peripheral blood is an area of firstly trying to explore the potency of cfDNA as a kind of tumor markers. For now, studies have confirmed that KARAS, EFGR, TP53, and APC are common tumor specific mutations in peripheral blood of patients with solid tumors [14-17, 76-78]. Tumor-suppressive gene TP53 mutation frequently occurs in patients with $\operatorname{HCC}[14,15] ; 50 \%$ of HCC patients living in areas exposed to aflatoxin have tumor suppressor gene P53 (R249S) point mutation, which means amino acid at 249 site AGG changes to AGT [16]. More importantly, point mutation of TP53 can be detected in cfDNA even in the early stage of HCC which is the only gene mutation that can be detected in the patient's circulatory system and is not observed in normal population [17]. Furthermore, patients with AG/GG at rs894151 or AC/CC at rs12438080 in circulating DNA were significantly associated with a decreased OS and TTR of HBV-related HCC patients after liver transplantation [79]. However, with the fact that the probability of gene mutation is relatively low and the enormous content of cfDNA in peripheral blood, thus, the detective method should have high sensitivity and specificity. Furthermore, the complicated extraction process can easily cause cfDNA loss, which will result in increased rate of falsenegative results. So, detective methods of cfDNA mutation with ability to overcome these problems will rapidly extend the application of cfDNA in clinic.

DNA copy number variations (CNVs) are distributed very commonly in the human genome and affect more than $10 \%$ of the genomic sequence [80]. Furthermore, in tumor patients, CNVs are common genomic changes which have a relatively stable and wide coverage and thus can be used to identify cancer susceptibility loci [18, 19, 8183]. The commonly amplified regions in HCC are at 1q, $8 \mathrm{q}, 7 \mathrm{q}, 17 \mathrm{q}$, and $20 \mathrm{q}$, and the common deleted regions are at $4 \mathrm{q}, 8 \mathrm{p}, 13 \mathrm{q}, 16 \mathrm{q}$, and $17 \mathrm{p}$ [20-22], such as CHD1L (1q21) [23] and DLC1 (8p22) [24]. Chan et al. confirmed the existence of typical DNA CNVs in the peripheral blood of 4 hepatocellular carcinoma patients by using massively parallel sequencing, and they almost all disappeared after surgical 
treatment [19]. Furthermore, oncogenes or antioncogenes usually exist in these regions containing CNVs, which means CNVs detection in these regions has great potency in the early diagnosis of HCC.

\section{DNA Methylation}

DNA methylation is an important epigenetic phenomenon, methylated sites are distributed globally on about $80 \%$ of CpGs islands [84], and $5^{\prime}$-end of the promoter region in $60 \%$ of the human genes contains $\mathrm{CpG}$ islands, the methylation of which plays an important role in regulating gene expression [85]. Changes of DNA methylation widely existed in tumors and played an important role in tumor progression, which is generally characterized by a wide range of genomic hypomethylation and hypermethylation [86-88]. Abnormal methylation occurs before cellular canceration and throughout all stages of malignant transformation, which have the characteristics of tissue specificity and long-term stability; thus, detection of aberrant gene methylation could serve as a potentially powerful approach for early diagnosis of tumors, such as lung cancer and breast cancer [89-91]. The most commonly used detective method is improved and methylation-specific PCR method $[92,93]$, which is relatively quick and easily performed, and it shows high sensitivity and accuracy to meet the clinical needs for methylation research and application.

Different from genes mutation, many studies have shown that the majority of methylated genes can be detected in the circulatory system of HCC patients, and the cfDNA methylation profile showed good consistency with methylation profile in tumor tissues [25-27, 94, 95]. Iyer et al. [25] detected the methylation statuses of APC, FHIT, p15, p16, and E-cadherin gene in 28 cases of HCC patients and found that methylated rates of these five genes in peripheral blood significantly and positively correlated with the methylated rates in tumor tissues and could well reflect the methylation status of abnormal genes in tumor tissues.

Detection of peripheral DNA methylation has great potential application in the diagnosis, prognosis, and efficacy evaluation of HCC, but the most concerning point is its diagnostic value [28-30, 96]. The Ras association domain family protein 1A (RASSF1A) is a tumor suppressor gene and frequently lost in human cancers by promoter-specific methylation [28, 96]. Chan et al. [28] showed that RASSF1A gene hypermethylation could be detected in the serum of $93 \%$ of HCC patients and $58 \%$ of the HBV carriers, while only $8 \%$ of healthy people had RASSF1A gene hypermethylation. More importantly, correlation analysis further identified that higher concentration of methylated fragments in serum predicted a shorter relapse-free survival time of HCC patients. HCC patients seropositive for the methylated cyclin D2 gene ( $>70 \mathrm{pg} / \mathrm{mL}$ serum) also exhibited a significantly shorter DFS period than patients who were seronegative for the methylated cyclin D2 gene [97].

Given the fact that a single gene methylation showed limited value in the diagnosis of HCC, combined detection of multiple genes methylation status is an effective way to improve the efficiency of diagnosis [31]. The sensitivity and specificity of a combined methylation detection of APC, RASSF1A, GSTP1, and SFRP1 in peripheral blood of HCC patients are $92.7 \%$ and $81.9 \%$, respectively [31]. Therefore, in order to improve the sensitivity of early diagnosis of HCC, search for more methylation-related genes involved in HCC progression has great potency in HCC diagnosis.

By now, as summarized in Table 1, multiple alterations in cfDNAs have been found in HCC patients. In the future, with the rapid development of digital PCR and gene sequencing technologies, we believe that the clinical detection of cfDNA variations in cancer patients will become achievable. More importantly, these technologies also provide an effective way for the discovery of additional cfDNA markers.

\section{Circulating miRNA}

Besides cfDNA, there is a certain level of circulating miRNA existing in the peripheral blood. miRNAs are a class of highly conserved noncoding single-stranded endogenous small molecule RNAs, typically 20-25 nt [98]. They are involved in multiple bioactivities of mammalian cells, including stem-cell self-renewal, cellular development, differentiation, proliferation, and apoptosis [99]. In the peripheral blood, endogenous mature miRNA mainly existed in the form of particle by binding with protein or lipoprotein to increase its stability and thus could withstand room temperature, repeated freezing and thawing, acid-base environment, DNA or RNA enzyme treatment, and also other complicated environmental factors $[100,101]$. miRNA expression profiling in different cancer types has distinct tissue specificity and expression levels and significantly correlates with tumor classification, diagnosis, and disease progression $[102,103]$. Thus, the existence of circulating miRNAs in the peripheral blood of cancer patients has raised the possibility that circulating miRNAs may serve as a kind of novel diagnostic or prognostic markers.

\section{Detection of Circulating miRNA in HCC Patients and Its Clinical Relevance}

As in HCC, although there is no clear miRNA expression profiling, studies have confirmed that several circulating miRNAs closely relate to the progression of HCC, mainly including miR-122, miR-200a, miR-21, miR-223, let-7f, and miR-155 [32-43, 104] (Table 2).

These circulating miRNAs showed great potency for clinical diagnosis of HCC. Yamamoto et al. [39] initially evaluated miRNAs expression in the serum of 10 patients with HCC and demonstrated that miR-500 is an oncofetal miRNA which was abundantly expressed in the sera of HCC patients and returned to normal after the surgical treatment. Zhang et al. [34] further identified that circulating miR-143 and miR-215 both have good diagnostic efficiency in human HCC; the sensitivity and specificity of miR- 143 were $78 \%$ and $64 \%$ and those of miR-215 were $78 \%$ and $89 \%$. Given the limited diagnostic value of a single circulating miRNA to HCC, some researchers combined circulating miRNA with AFP to diagnose HCC. The sensitivity and specificity of single miR-21 diagnosis are $60 \%$ and $83 \%$, respectively, and the 
TABLE 1: Summary of the role and findings for circulating DNA in HCC.

\begin{tabular}{|c|c|c|c|c|}
\hline Type of alteration & Gene & Location & Biomarker & References \\
\hline \multirow[b]{2}{*}{ Single nucleotide mutations } & TP53 & $17 \mathrm{p} 13.1$ & Diagnosis & {$[14-16]$} \\
\hline & CTNNB1 & $3 \mathrm{p} 21$ & $\begin{array}{c}\text { Predictor (exposure to different viral and } \\
\text { environmental factors) }\end{array}$ & {$[17]$} \\
\hline \multirow{6}{*}{ Copy number variation } & NA & $1 \mathrm{p} / 1 \mathrm{q} / 8 \mathrm{p} / 8 \mathrm{q}$ & Diagnosis & [18] \\
\hline & NA & $7 q / 8 q / 13 q / 14 p$ & Diagnosis & {$[19]$} \\
\hline & NA & $1 \mathrm{q}, 8 \mathrm{q}, 7 \mathrm{q}, 17 \mathrm{q}, 20 \mathrm{q}$ & Diagnosis & {$[20-22]$} \\
\hline & NA & $4 q, 8 p, 13 q, 16 q, 17 p$ & Diagnosis & {$[20-22]$} \\
\hline & CHD1L & $1 \mathrm{q} 21$ & Diagnosis & {$[23]$} \\
\hline & DLC1 & $8 \mathrm{p} 22$ & Diagnosis & {$[24]$} \\
\hline \multirow{9}{*}{ Methylation changes } & APC & $5 q 21-q 22$ & Diagnosis & {$[25,26]$} \\
\hline & $\mathrm{P} 15 / \mathrm{P} 16$ & 9 p21 & Diagnosis & {$[25,27]$} \\
\hline & RASSF1A & $3 \mathrm{p} 21.3$ & Diagnosis & {$[28]$} \\
\hline & TRG5 & $16 \mathrm{q} 22.1$ & Diagnosis & [29] \\
\hline & HOXA9 & $7 \mathrm{p} 15.2$ & Diagnosis & {$[30]$} \\
\hline & FHIT & $3 \mathrm{p} 14.2$ & Diagnosis & {$[25]$} \\
\hline & E-caherin & $16 \mathrm{q} 22.1$ & Diagnosis & {$[25]$} \\
\hline & GSTP1 & $11 q 13.2$ & Diagnosis & {$[31]$} \\
\hline & SFRP1 & $8 \mathrm{p} 11.21$ & Diagnosis & [31] \\
\hline
\end{tabular}

NA: not available.

TABLE 2: miRNAs found deregulated in hepatocellular carcinoma.

\begin{tabular}{|c|c|c|c|c|}
\hline miRNA & Deregulation & Method & Number of subjects & Reference \\
\hline $\begin{array}{l}\text { miR-1, miR-25, miR-92a, miR-206, } \\
\text { miR-375, and let-7f }\end{array}$ & Up & Solexia sequencing, qRT-PCR & $\begin{array}{c}120 \mathrm{HCC}, 135 \mathrm{HBV}, 48 \mathrm{HCV} \text {, and } 210 \\
\text { controls }\end{array}$ & {$[32]$} \\
\hline miR-21 & Up & qRT-PCR & $\begin{array}{c}126 \mathrm{HCC}, 30 \mathrm{CHB} \text {, and } 50 \text { healthy } \\
\text { subjects }\end{array}$ & {$[33]$} \\
\hline miR-143 and miR-215 & Up & $\begin{array}{l}\text { qRT-PCR/TaqMan miRNA } \\
\text { assays }\end{array}$ & $\begin{array}{c}95 \mathrm{HCC}, 118 \text { hepatitis carriers, and } 127 \\
\text { controls }\end{array}$ & {$[34]$} \\
\hline miR-155 & Up & qRT-PCR & $\begin{array}{c}10 \mathrm{HCV}-\mathrm{HCC}, 34 \mathrm{HCV}, 12 \mathrm{NASH} \text {, and } \\
7 \text { healthy subjects }\end{array}$ & [35] \\
\hline miR-15b and miR-130b & Up & qRT-PCR & 57 HCC, 29 HBC, and 30 controls & {$[36]$} \\
\hline miR-125b & Up & BioMark $^{\mathrm{TM}}$ Dynamic Array & $\begin{array}{c}20 \mathrm{HBV} \text {-positive HCC, } 24 \mathrm{CHB}, 22 \\
\text { HBV-positive cirrhosis, and } 28 \\
\text { controls }\end{array}$ & [37] \\
\hline miR-221, miR-222, and miR-224 & Up & qRT-PCR & $46 \mathrm{HCC}$ and 20 controls & {$[38]$} \\
\hline miR-500 & Up & qRT-PCR & $10 \mathrm{HCC}$ & [39] \\
\hline miR-16 and miR-199a & Down & qRT-PCR & $\begin{array}{c}105 \text { HCC patients, } 107 \text { CLD, and } 71 \\
\text { controls }\end{array}$ & {$[40]$} \\
\hline miR-122 & Down & qRT-PCR & $62 \mathrm{HCC}, 48 \mathrm{CLD}$, and 34 controls & {$[41]$} \\
\hline miR-29 & Down & qRT-PCR & $17 \mathrm{HCC}$ and 17 controls & {$[42]$} \\
\hline miR-152 & Down & qRT-PCR & $89 \mathrm{HCC}$ and 89 controls & {$[43]$} \\
\hline miR-200a & Down & qRT-PCR & $41 \mathrm{HCC}$ and 41 controls & [43] \\
\hline $\operatorname{miR} 223-3 p$ & Down & BioMark Dynamic Array & $\begin{array}{c}20 \mathrm{HBV} \text {-positive HCC, } 24 \mathrm{CHB}, 22 \\
\text { HBV-positive cirrhosis, and } 28 \\
\text { controls }\end{array}$ & [37] \\
\hline
\end{tabular}


area of $95 \%$ confidence interval under ROC curve was $0.69-$ 0.86 . However, when combined with AFP, the sensitivity was $81 \%$, specificity of $77 \%$, the area of $95 \%$ confidence interval under the ROC curve was 0.74-0.90, significantly higher than the traditional markers AFP (0.54-0.82), and the diagnostic efficiency was greatly improved [33]. The early diagnosis of HCC is clinically desirable, as the prognosis of HCC is significantly improved if the patients get therapy early on. Though circulating miRNAs could be used as prognostic biomarkers for various types of cancers, including colorectal cancer and hematologic cancers [105] and study has confirmed that serum high level of miR-221 expression was correlated with tumor size, cirrhosis, and tumor stage of HCC [38], the prognostic value of circulating miRNAs in $\mathrm{HCC}$ is still less reported, which may be owing to the fact that the 5 -year overall survival rate of HCC is still only $0 \%-10 \%$.

Currently, circulating miRNAs' detection is mostly based on quantitative PCR (qPCR); however, before translation into clinical application, it still requires further steps to standardize and validate the technical process employed to measure circulating miRNAs by qPCR. Compared with qPCR, digital PCR (dPCR) has many advantages, which gets the absolute expressive level of miRNA without the standard curve and is not affected by variations caused from samples and PCR amplification efficiency [106]. In lung cancer diagnosis, detection of plasma miRNAs by digital PCR could quantify low abundance of miRNAs with high reproducibility and has showed high sensitivity and specificity in distinguishing lung cancer patients from cancer-free subjects $[107,108]$. The application of APCR in HCC diagnosis is still less reported but it provides a strong guarantee for further development of circulating miRNAs as diagnostic or prognostic biomarkers.

\section{Conclusion and Outlook}

Numerous genetic and epigenetic alterations contribute to oncogenesis and cancer progression, and the progression of cancer is characterized by high heterogeneity. Tumors acquire new mutations that render them resistant to the therapies that target specific genetic mutations. Thus, to improve the clinical outcomes in malignant tumors including HCC, a comprehensive surveillance system comprised early and accurate diagnosis, and dynamic tumor monitoring is necessary. In this regard, a liquid biopsy may capture the entire heterogeneity of tumors. What is more, tumor genotypes are notoriously unstable and prone to changes under selection pressure; thus, liquid biopsies showed great advantages compared to tissue biopsies with regard to the clinical risks of tumor patients and cost, as well as the feasibility of taking serial samples in order to monitor tumor genomic changes in real time.

In terms of liquid biopsy, CTCs have been the most studied as they provide information of tumor progression at both the genetic and cellular levels, while CTCs are relatively rare and require sensitive collection and enrichment technology. cfNAs are emerging as an effective alternative to CTCs, with the benefits of easier collection and analysis. With the expanded application of digital PCR and 3rdgeneration sequencing technologies, cfNAs-based detection of liquid biopsies has great potency in early diagnosis and prognostic evaluation of tumors. The personalized information comprised in cfNAs could enable physicians to make more systematic and precise medical decisions.

However, in the past few years, experimental design and detective methods of CTCs and cfNAs in the studies are quite different, with relatively small sample size, which resulted in low stability and comparability in the experimental data across studies. Standardization of detective methods will be a key factor to ensure consistency in clinical application. With the standardization in blood collection and processing and storage and DNA extraction and quantification and analysis and reporting of data, CTCs and cfNAs existing in liquid biopsy might serve as promising detective biomarkers in therapeutic monitoring, prognostic evaluation, and risk assessment of HCC.

\section{Competing Interests}

No potential conflict of interests was disclosed.

\section{Authors' Contributions}

Chang-Qing Yin and Chun-Hui Yuan contributed equally to this work.

\section{Acknowledgments}

This work was supported by National Natural Science Foundation of China (no. 81371897) and Natural Science Foundation of Hubei Province (no. 2013CFA027) and research grants from the Independent Research Fund Program of Wuhan University (no. 2042014kf0241) and Hubei Province Health and Family Planning Scientific Research Project (WJ2015MB032). This work was also funded by "351 Talent Project (Luojia Young Scholars)” of Wuhan University.

\section{References}

[1] WHO, GLOBOCAN 2012: Estimated Cancer Incidence, Mortality and Prevalence Worldwide in 2012, 2012, http://globocan .iarc.fr/Default.aspx.

[2] P. A. Farazi and R. A. DePinho, "Hepatocellular carcinoma pathogenesis: from genes to environment," Nature Reviews Cancer, vol. 6, no. 9, pp. 674-687, 2006.

[3] R. Siegel, E. Ward, O. Brawley, and A. Jemal, "Cancer statistics, 2011: the impact of eliminating socioeconomic and racial disparities on premature cancer deaths," CA: A Cancer Journal for Clinicians, vol. 61, no. 4, pp. 212-236, 2011.

[4] J. M. Llovet, A. Burroughs, and J. Bruix, "Hepatocellular carcinoma," The Lancet, vol. 362, no. 9399, pp. 1907-1917, 2003.

[5] J.Zhou, Y.-H. Shi, and J. Fan, "Circulating cell-free nucleic acids: promising biomarkers of hepatocellular carcinoma," Seminars in Oncology, vol. 39, no. 4, pp. 440-448, 2012.

[6] J. W. Park, "Practice guideline for diagnosis and treatment of hepatocellular carcinoma," The Korean Journal of Hepatology, vol. 10, no. 2, pp. 88-98, 2004.

[7] N. Rich and A. G. Singal, "Hepatocellular carcinoma tumour markers: current role and expectations," Best Practice and 
Research: Clinical Gastroenterology, vol. 28, no. 5, pp. 843-853, 2014.

[8] N. M. Forones, L. A. Queiroz, M. L. Ferraz, and E. R. Parise, "Alphafetoprotein in hepatic tumours and benign liver diseases," Revista da Associação Médica Brasileira, vol. 41, no. 2, pp. 91-93, 1995.

[9] D. S. Chen and J. L. Sung, "Serum alphafetoprotein in hepatocellular carcinoma," Cancer, vol. 40, no. 2, pp. 779-783, 1977.

[10] N. Karachaliou, C. Mayo-de-las-Casas, M. A. Molina-Vila, and R. Rosell, "Real-time liquid biopsies become a reality in cancer treatment," Annals of Translational Medicine, vol. 3, no. 3, article 36, 2015.

[11] S. Sestini, M. Boeri, A. Marchiano et al., "Circulating microRNA signature as liquid-biopsy to monitor lung cancer in low-dose computed tomography screening," Oncotarget, vol. 6, no. 32, pp. 32868-32877, 2015.

[12] T. R. Ashworth, "A case of cancer in which cells similar to those in the tumours were seen in the blood after death," Australasian Medical Journal, vol. 14, pp. 146-149, 1869.

[13] M. C. Miller, G. V. Doyle, and L. W. Terstappen, "Significance of circulating tumor cells detected by the cellsearch system in patients with metastatic breast colorectal and prostate cancer," Journal of Oncology, vol. 2010, Article ID 617421, 8 pages, 2010.

[14] H. G. Woo, X. W. Wang, A. Budhu et al., "Association of TP53 mutations with stem cell-like gene expression and survival of patients with hepatocellular carcinoma," Gastroenterology, vol. 140, no. 3, pp. 1063-1070, 2011.

[15] K. Szymañska, J.-G. Chen, Y. Cui et al., “TP53 R249S mutations, exposure to aflatoxin, and occurrence of hepatocellular carcinoma in a cohort of chronic hepatitis B virus carriers from Qidong, China," Cancer Epidemiology Biomarkers and Prevention, vol. 18, no. 5, pp. 1638-1643, 2009.

[16] S. Villar, E. Le Roux-Goglin, D. A. Gouas et al., "Seasonal variation in Tp53 R249S-mutated serum DNA with aflatoxin exposure and hepatitis B virus infection," Environmental Health Perspectives, vol. 119, no. 11, pp. 1635-1640, 2011.

[17] G. Hosny, N. Farahat, H. Tayel, and P. Hainaut, "Ser-249 TP53 and CTNNB1 mutations in circulating free DNA of Egyptian patients with hepatocellular carcinoma versus chronic liver diseases," Cancer Letters, vol. 264, no. 2, pp. 201-208, 2008.

[18] P. Jiang, C. W. M. Chan, K. C. A. Chan et al., "Lengthening and shortening of plasma DNA in hepatocellular carcinoma patients," Proceedings of the National Academy of Sciences of the United States of America, vol. 112, no. 11, pp. E1317-E1325, 2015.

[19] K. C. A. Chan, P. Jiang, Y. W. L. Zheng et al., "Cancer genome scanning in plasma: detection of tumor-associated copy number aberrations, single-nucleotide variants, and tumoral heterogeneity by massively parallel sequencing," Clinical Chemistry, vol. 59, no. 1, pp. 211-224, 2013.

[20] Y. Midorikawa, W. Tang, and Y. Sugiyama, "High-resolution mapping of copy number aberrations and identification of target genes in hepatocellular carcinoma," BioScience Trends, vol. 1, no. 1, pp. 26-32, 2007.

[21] M. A. Patil, I. Gütgemann, J. Zhang et al., "Array-based comparative genomic hybridization reveals recurrent chromosomal aberrations and Jab1 as a potential target for $8 \mathrm{q}$ gain in hepatocellular carcinoma," Carcinogenesis, vol. 26, no. 12, pp. 2050-2057, 2005.

[22] D. Jia, L. Wei, W. Guo et al., "Genome-wide copy number analyses identified novel cancer genes in hepatocellular carcinoma," Hepatology, vol. 54, no. 4, pp. 1227-1236, 2011.
[23] N.-F. Ma, L. Hu, J. M. Fung et al., "Isolation and characterization of a novel oncogene, amplified in liver cancer 1, within a commonly amplified region at 1q21 in hepatocellular carcinoma," Hepatology, vol. 47, no. 2, pp. 503-510, 2008.

[24] B.-Z. Yuan, M. J. Miller, C. L. Keck, D. B. Zimonjic, S. S. Thorgeirsson, and N. C. Popescu, "Cloning, characterization, and chromosomal localization of a gene frequently deleted in human liver cancer (DLC-1) homologous to rat RhoGAP," Cancer Research, vol. 58, no. 10, pp. 2196-2199, 1998.

[25] P. Iyer, A.-R. Zekri, C.-W. Hung et al., "Concordance of DNA methylation pattern in plasma and tumor DNA of Egyptian hepatocellular carcinoma patients," Experimental and Molecular Pathology, vol. 88, no. 1, pp. 107-111, 2010.

[26] H. Chang, B. Yi, L. Li et al., "Methylation of tumor associated genes in tissue and plasma samples from liver disease patients," Experimental and Molecular Pathology, vol. 85, no. 2, pp. 96100, 2008.

[27] Y.-J. Zhang, H.-C. Wu, J. Shen et al., "Predicting hepatocellular carcinoma by detection of aberrant promoter methylation in serum DNA," Clinical Cancer Research, vol. 13, no. 8, pp. 23782384, 2007.

[28] K. C. A. Chan, P. B. S. Lai, T. S. K. Mok et al., "Quantitative analysis of circulating methylated DNA as a biomarker for hepatocellular carcinoma," Clinical Chemistry, vol. 54, no. 9, pp. 1528-1536, 2008.

[29] L.-Y. Han, Y.-C. Fan, N.-N. Mu et al., "Aberrant DNA methylation of G-protein-coupled bile acid receptor Gpbarl (TGR5) is a potential biomarker for hepatitis B virus associated hepatocellular carcinoma," International Journal of Medical Sciences, vol. 11, no. 2, pp. 164-171, 2014.

[30] C.-C. Kuo, C.-Y. Lin, Y.-L. Shih et al., "Frequent methylation of HOXA9 gene in tumor tissues and plasma samples from human hepatocellular carcinomas," Clinical Chemistry and Laboratory Medicine, vol. 52, no. 8, pp. 1235-1245, 2014.

[31] Z.-H. Huang, Y. Hu, D. Hua, Y.-Y. Wu, M.-X. Song, and Z.H. Cheng, "Quantitative analysis of multiple methylated genes in plasma for the diagnosis and prognosis of hepatocellular carcinoma," Experimental and Molecular Pathology, vol. 91, no. 3, pp. 702-707, 2011.

[32] L.-M. Li, Z.-B. Hu, Z.-X. Zhou et al., "Serum microRNA profiles serve as novel biomarkers for HBV infection and diagnosis of HBV-positive hepatocarcinoma," Cancer Research, vol. 70, no. 23, pp. 9798-9807, 2010.

[33] Y. Tomimaru, H. Eguchi, H. Nagano et al., "Circulating microRNA-21 as a novel biomarker for hepatocellular carcinoma," Journal of Hepatology, vol. 56, no. 1, pp. 167-175, 2012.

[34] Z.-Q. Zhang, H. Meng, N. Wang et al., "Serum microRNA 143 and microRNA 215 as potential biomarkers for the diagnosis of chronic hepatitis and hepatocellular carcinoma," Diagnostic Pathology, vol. 9, no. 1, article 135, 2014.

[35] Y. Zhang, W. Wei, N. Cheng et al., "Hepatitis C virus-induced up-regulation of microRNA-155 promotes hepatocarcinogenesis by activating Wnt signaling," Hepatology, vol. 56, no. 5, pp. 1631-1640, 2012.

[36] A. M. Liu, T.-J. Yao, W. Wang et al., "Circulating miR-15b and miR-130b in serum as potential markers for detecting hepatocellular carcinoma: a retrospective cohort study," $B M J$ Open, vol. 2, no. 2, Article ID e000825, 2012.

[37] B. G. Giray, G. Emekdas, S. Tezcan et al., "Profiles of serum microRNAs; miR-125b-5p and miR223-3p serve as novel biomarkers for HBV-positive hepatocellular carcinoma," Molecular Biology Reports, vol. 41, no. 7, pp. 4513-4519, 2014. 
[38] J. Li, Y. Wang, W. Yu, J. Chen, and J. Luo, "Expression of serum miR-221 in human hepatocellular carcinoma and its prognostic significance," Biochemical and Biophysical Research Communications, vol. 406, no. 1, pp. 70-73, 2011.

[39] Y. Yamamoto, N. Kosaka, M. Tanaka et al., "MicroRNA-500 as a potential diagnostic marker for hepatocellular carcinoma," Biomarkers, vol. 14, no. 7, pp. 529-538, 2009.

[40] K. Z. Qu, K. Zhang, H. Li, N. H. Afdhal, and M. Albitar, "Circulating microRNAs as biomarkers for hepatocellular carcinoma," Journal of Clinical Gastroenterology, vol. 45, no. 4, pp. 355-360, 2011.

[41] P. Qi, S.-Q. Cheng, H. Wang, N. Li, Y.-F. Chen, and C.F. Gao, "Serum microRNAs as biomarkers for hepatocellular carcinoma in Chinese patients with chronic hepatitis B virus infection," PLoS ONE, vol. 6, no. 12, Article ID e28486, 2011.

[42] Y. Xiong, J.-H. Fang, J.-P. Yun et al., "Effects of microRNA-29 on apoptosis, tumorigenicity, and prognosis of hepatocellular carcinoma," Hepatology, vol. 51, no. 3, pp. 836-845, 2010.

[43] J.-H. Yuan, F. Yang, B.-F. Chen et al., “The histone deacetylase 4/SP1/microrna-200a regulatory network contributes to aberrant histone acetylation in hepatocellular carcinoma," Hepatology, vol. 54, no. 6, pp. 2025-2035, 2011.

[44] G. Vona, L. Estepa, C. Béroud et al., "Impact of cytomorphological detection of circulating tumor cells in patients with liver cancer," Hepatology, vol. 39, no. 3, pp. 792-797, 2004.

[45] M. G. Krebs, R. L. Metcalf, L. Carter, G. Brady, F. H. Blackhall, and C. Dive, "Molecular analysis of circulating tumour cellsbiology and biomarkers," Nature Reviews Clinical Oncology, vol. 11, no. 3, pp. 129-144, 2014.

[46] Y.-F. Sun, Y. Xu, X.-R. Yang et al., "Circulating stem cell-like epithelial cell adhesion molecule-positive tumor cells indicate poor prognosis of hepatocellular carcinoma after curative resection," Hepatology, vol. 57, no. 4, pp. 1458-1468, 2013.

[47] S. Riethdorf, H. Fritsche, V. Müller et al., "Detection of circulating tumor cells in peripheral blood of patients with metastatic breast cancer: a validation study of the CellSearch system," Clinical Cancer Research, vol. 13, no. 3, pp. 920-928, 2007.

[48] E. W. Thompson and I. Haviv, “The social aspects of EMT-MET plasticity," Nature Medicine, vol. 17, no. 9, pp. 1048-1049, 2011.

[49] S. Nagrath, L. V. Sequist, S. Maheswaran et al., "Isolation of rare circulating tumour cells in cancer patients by microchip technology," Nature, vol. 450, no. 7173, pp. 1235-1239, 2007.

[50] S. L. Stott, L. Richard, S. Nagrath et al., "Isolation and characterization of circulating tumor cells from patients with localized and metastatic prostate cancer," Science Translational Medicine, vol. 2, no. 25, pp. 25-ra23, 2010.

[51] X. Yu, B. Wang, N. Zhang et al., "Capture and release of cancer cells by combining on-chip purification and off-chip enzymatic treatment," ACS Applied Materials and Interfaces, vol. 7, no. 43, pp. 24001-24007, 2015.

[52] W. Guo, X.-R. Yang, Y.-F. Sun et al., "Clinical significance of EpCAM mRNA-positive circulating tumor cells in hepatocellular carcinoma by an optimized negative enrichment and qRTPCR-based platform," Clinical Cancer Research, vol. 20, no. 18, pp. 4794-4805, 2014.

[53] G. H. Choi, G. I. Kim, J. E. Yoo et al., "Increased expression of circulating cancer stem cell markers during the perioperative period predicts early recurrence after curative resection of hepatocellular carcinoma," Annals of Surgical Oncology, vol. 22, supplement 3, pp. S1444-S1452, 2015.
[54] N. N. Rahbari, C. Reissfelder, M. Mühlbayer et al., "Correlation of circulating angiogenic factors with circulating tumor cells and disease recurrence in patients undergoing curative resection for colorectal liver metastases," Annals of Surgical Oncology, vol. 18, no. 8, pp. 2182-2191, 2011.

[55] Z.-T. Fang, W. Zhang, G.-Z. Wang et al., "Circulating tumor cells in the central and peripheral venous compartment-assessing hematogenous dissemination after transarterial chemoembolization of hepatocellular carcinoma," OncoTargets and Therapy, vol. 7, pp. 1311-1318, 2014.

[56] S. Liu, N. Li, X. Yu et al., "Expression of intercellular adhesion molecule 1 by hepatocellular carcinoma stem cells and circulating tumor cells," Gastroenterology, vol. 144, no. 5, pp. 10311041.e10, 2013.

[57] M. Yao, D.-F. Yao, Y.-Z. Bian et al., "Values of circulating GPC-3 mRNA and alpha-fetoprotein in detecting patients with hepatocellular carcinoma," Hepatobiliary and Pancreatic Diseases International, vol. 12, no. 2, pp. 171-179, 2013.

[58] J.-L. Fan, Y.-F. Yang, C.-H. Yuan, H. Chen, and F.-B. Wang, "Circulating tumor cells for predicting the prognostic of patients with hepatocellular carcinoma: a meta analysis," Cellular Physiology and Biochemistry, vol. 37, no. 2, pp. 629-640, 2015.

[59] J. Kaiser, "Medicine. Keeping tabs on tumor DNA," Science, vol. 327, no. 5969, p. 1074, 2010.

[60] M. Raponi, L. Dossey, T. Jatkoe et al., "MicroRNA classifiers for predicting prognosis of squamous cell lung cancer," Cancer Research, vol. 69, no. 14, pp. 5776-5783, 2009.

[61] V. García, J. M. García, C. Peña et al., "Free circulating mRNA in plasma from breast cancer patients and clinical outcome," Cancer Letters, vol. 263, no. 2, pp. 312-320, 2008.

[62] P. Mandel and P. Métais, "Les acides nucleiques du plasma sanguin chez l'homme," Comptes Rendus de l'Académie des Sciences de Paris, vol. 142, pp. 241-243, 1948.

[63] G. D. Sorenson, D. M. Pribish, F. H. Valone, V. A. Memoli, D. J. Bzik, and S.-L. Yao, "Soluble normal and mutated DNA sequences from single-copy genes in human blood," Cancer Epidemiology Biomarkers and Prevention, vol. 3, no. 1, pp. 6771, 1994.

[64] V. Vasioukhin, P. Anker, P. Maurice, J. Lyautey, C. Lederrey, and M. Stroun, "Point mutations of the N-ras gene in the blood plasma DNA of patients with myelodysplastic syndrome or acute myelogenous leukaemia," British Journal of Haematology, vol. 86, no. 4, pp. 774-779, 1994.

[65] M. Fleischhacker and B. Schmidt, "Circulating nucleic acids (CNAs) and cancer-a survey," Biochimica et Biophysica ActaReviews on Cancer, vol. 1775, no. 1, pp. 181-232, 2007.

[66] A. K. Pathak, M. Bhutani, S. Kumar, A. Mohan, and R. Guleria, "Circulating cell-free DNA in plasma/serum of lung cancer patients as a potential screening and prognostic tool," Clinical Chemistry, vol. 52, no. 10, pp. 1833-1842, 2006.

[67] H. X. Si, S. W. Tsao, C. S. P. Poon, L. D. Wang, Y. C. Wong, and A. L. M. Cheung, "Viral load of HPV in esophageal squamous cell carcinoma," International Journal of Cancer, vol. 103, no. 4, pp. 496-500, 2003.

[68] N. G. Coufal, J. L. Garcia-Perez, G. E. Peng et al., "L1 retrotransposition in human neural progenitor cells," Nature, vol. 460, no. 7259, pp. 1127-1131, 2009.

[69] J. Wang, K.-Y. Zhang, S.-M. Liu, and S. Sen, "Tumor-associated circulating microRNAs as biomarkers of cancer," Molecules, vol. 19, no. 2, pp. 1912-1938, 2014. 
[70] J.-J. Choi, C. F. Reich III, and D. S. Pisetsky, "The role of macrophages in the in vitro generation of extracellular DNA from apoptotic and necrotic cells," Immunology, vol. 115, no. 1, pp. 55-62, 2005.

[71] Z. Huang, D. Hua, Y. Hu et al., "Quantitation of plasma circulating DNA using quantitative PCR for the detection of hepatocellular carcinoma," Pathology and Oncology Research, vol. 18, no. 2, pp. 271-276, 2012.

[72] N. Ren, Q.-H. Ye, L.-X. Qin, B.-H. Zhang, Y.-K. Liu, and Z.-Y. Tang, "Circulating DNA level is negatively associated with the long-term survival of hepatocellular carcinoma patients," World Journal of Gastroenterology, vol. 12, no. 24, pp. 3911-3914, 2006.

[73] T. M. H. Gall, A. E. Frampton, J. Krell et al., "Cell-free DNA for the detection of pancreatic, liver and upper gastrointestinal cancers: has progress been made?" Future Oncology, vol. 9, no. 12, pp. 1861-1869, 2013.

[74] Y. I. Elshimali, H. Khaddour, M. Sarkissyan, Y. Wu, and J. V. Vadgama, "The clinical Utilization of circulating cell free DNA (CCFDNA) in blood of cancer patients," International Journal of Molecular Sciences, vol. 14, no. 9, pp. 18925-18958, 2013.

[75] B. Ralla, C. Stephan, S. Meller, D. Dietrich, G. Kristiansen, and K. Jung, "Nucleic acid-based biomarkers in body fluids of patients with urologic malignancies," Critical Reviews in Clinical Laboratory Sciences, vol. 51, no. 4, pp. 200-231, 2014.

[76] S. Maheswaran, L. V. Sequist, S. Nagrath et al., "Detection of mutations in EGFR in circulating lung-cancer cells," The New England Journal of Medicine, vol. 359, no. 4, pp. 366-377, 2008.

[77] Z.-M. Shao, J. Wu, Z.-Z. Shen, and M. Nguyen, "p53 mutation in plasma DNA and its prognostic value in breast cancer patients," Clinical Cancer Research, vol. 7, no. 8, pp. 2222-2227, 2001.

[78] J.-Y. Wang, J.-S. Hsieh, M.-Y. Chang et al., "Molecular detection of APC, K-ras, and p53 mutations in the serum of colorectal cancer patients as circulating biomarkers," World Journal of Surgery, vol. 28, no. 7, pp. 721-726, 2004.

[79] J. Hu, Z. Wang, J. Fan et al., "Genetic variations in plasma circulating DNA of HBV-related hepatocellular carcinoma patients predict recurrence after liver transplantation," PLOS ONE, vol. 6, no. 10, Article ID e26003, 2011.

[80] R. Redon, S. Ishikawa, K. R. Fitch et al., "Global variation in copy number in the human genome," Nature, vol. 444, no. 7118, pp. 444-454, 2006.

[81] P. A. Futreal, L. Coin, M. Marshall et al., "A census of human cancer genes," Nature Reviews Cancer, vol. 4, no. 3, pp. 177-183, 2004.

[82] T. Santarius, J. Shipley, D. Brewer, M. R. Stratton, and C. S. Cooper, "A census of amplified and overexpressed human cancer genes," Nature Reviews Cancer, vol. 10, no. 1, pp. 59-64, 2010.

[83] A. Kallioniemi, "CGH microarrays and cancer," Current Opinion in Biotechnology, vol. 19, no. 1, pp. 36-40, 2008.

[84] R. Jaenisch and A. Bird, "Epigenetic regulation of gene expression: how the genome integrates intrinsic and environmental signals," Nature Genetics, vol. 33, supplement, pp. 245-254, 2003.

[85] S. B. Baylin, "DNA methylation and gene silencing in cancer," Nature Clinical Practice Oncology, vol. 2, supplement 1, pp. S4S11, 2005.

[86] P. A. Jones and S. B. Baylin, "The fundamental role of epigenetic events in cancer," Nature Reviews Genetics, vol. 3, no. 6, pp. 415$428,2002$.
[87] P. A. Jones and P. W. Laird, "Cancer epigenetics comes of age," Nature Genetics, vol. 21, no. 2, pp. 163-167, 1999.

[88] P. A. Jones and S. B. Baylin, "The epigenomics of cancer," Cell, vol. 128, no. 4, pp. 683-692, 2007.

[89] W. A. Palmisano, K. K. Divine, G. Saccomanno et al., "Predicting lung cancer by detecting aberrant promoter methylation in sputum," Cancer Research, vol. 60, no. 21, pp. 5954-5958, 2000.

[90] M. Esteller, M. Sanchez-Cespedes, R. Resell, D. Sidransky, S. B. Baylin, and J. G. Herman, "Detection of aberrant promoter hypermethylation of tumor suppressor genes in serum DNA from non-small cell lung cancer patients," Cancer Research, vol. 59, no. 1, pp. 67-70, 1999.

[91] E. Evron, W. C. Dooley, C. B. Umbricht et al., "Detection of breast cancer cells in ductal lavage fluid by methylation-specific PCR," The Lancet, vol. 357, no. 9265, pp. 1335-1336, 2001.

[92] S. E. Cottrell, J. Distler, N. S. Goodman et al., "A real-time PCR assay for DNA-methylation using methylation-specific blockers," Nucleic Acids Research, vol. 32, no. 1, article e10, 2004.

[93] C. A. Eads, K. D. Danenberg, K. Kawakami et al., "MethyLight: a high-throughput assay to measure DNA methylation," Nucleic Acids Research, vol. 28, no. 8, p. E32, 2000.

[94] I. H. N. Wong, Y. M. D. Lo, J. Zhang et al., "Detection of aberrant p16 methylation in the plasma and serum of liver cancer patients," Cancer Research, vol. 59, no. 1, pp. 71-73, 1999.

[95] I. H. N. Wong, J. Zhang, P. B. S. Lai, W. Y. Lau, and Y. M. D. Lo, "Quantitative analysis of tumor-derived methylated p16INK4a sequences in plasma, serum, and blood cells of hepatocellular carcinoma patients," Clinical Cancer Research, vol. 9, no. 3, pp. 1047-1052, 2003.

[96] A. Agathanggelou, S. Honorio, D. P. Macartney et al., "Methylation associated inactivation of RASSF1A from region 3p21.3 in lung, breast and ovarian tumours," Oncogene, vol. 20, no. 12, pp. 1509-1518, 2001.

[97] M. Tsutsui, N. Iizuka, T. Moribe et al., "Methylated cyclin D2 gene circulating in the blood as a prognosis predictor of hepatocellular carcinoma," Clinica Chimica Acta, vol. 411, no. 78, pp. 516-520, 2010.

[98] J. Jiang, E. J. Lee, Y. Gusev, and T. D. Schmittgen, "Real-time expression profiling of microRNA precursors in human cancer cell lines," Nucleic Acids Research, vol. 33, no. 17, pp. 5394-5403, 2005.

[99] V. Ambros, "MicroRNA pathways in flies and worms: growth, death, fat, stress, and timing," Cell, vol. 113, no. 6, pp. 673-676, 2003.

[100] B. L. Jackson, A. Grabowska, and H. L. Ratan, "MicroRNA in prostate cancer: functional importance and potential as circulating biomarkers," BMC Cancer, vol. 14, no. 1, article 930, 2014.

[101] F. Mar-Aguilar, J. A. Mendoza-Ramírez, I. Malagón-Santiago et al., "Serum circulating microRNA profiling for identification of potential breast cancer biomarkers," Disease Markers, vol. 34, no. 3, pp. 163-169, 2013.

[102] N. Rosenfeld, R. Aharonov, E. Meiri et al., "MicroRNAs accurately identify cancer tissue origin," Nature Biotechnology, vol. 26, no. 4, pp. 462-469, 2008.

[103] J. Lu, G. Getz, E. A. Miska et al., "MicroRNA expression profiles classify human cancers," Nature, vol. 435, no. 7043, pp. 834-838, 2005.

[104] Y.-W. Dang, J. Zeng, R.-Q. He, M.-H. Rong, D.-Z. Luo, and G. Chen, "Effects of miR-152 on cell growth inhibition, motility 
suppression and apoptosis induction in hepatocellular carcinoma cells," Asian Pacific Journal of Cancer Prevention, vol. 15, no. 12, pp. 4969-4976, 2014.

[105] G. Cheng, "Circulating miRNAs: roles in cancer diagnosis, prognosis and therapy," Advanced Drug Delivery Reviews, vol. 81, pp. 75-93, 2015.

[106] C. M. Hindson, J. R. Chevillet, H. A. Briggs et al., "Absolute quantification by droplet digital PCR versus analog real-time PCR," Nature Methods, vol. 10, no. 10, pp. 1003-1005, 2013.

[107] J. Ma, N. Li, M. Guarnera, and F. Jiang, "Quantification of plasma miRNAs by digital PCR for cancer diagnosis," Biomarker Insights, vol. 8, pp. 127-136, 2013.

[108] N. Li, J. Ma, M. A. Guarnera, H. Fang, L. Cai, and F. Jiang, "Digital PCR quantification of miRNAs in sputum for diagnosis of lung cancer," Journal of Cancer Research and Clinical Oncology, vol. 140, no. 1, pp. 145-150, 2014. 


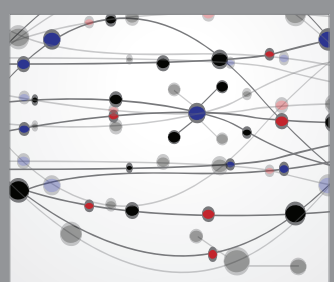

The Scientific World Journal
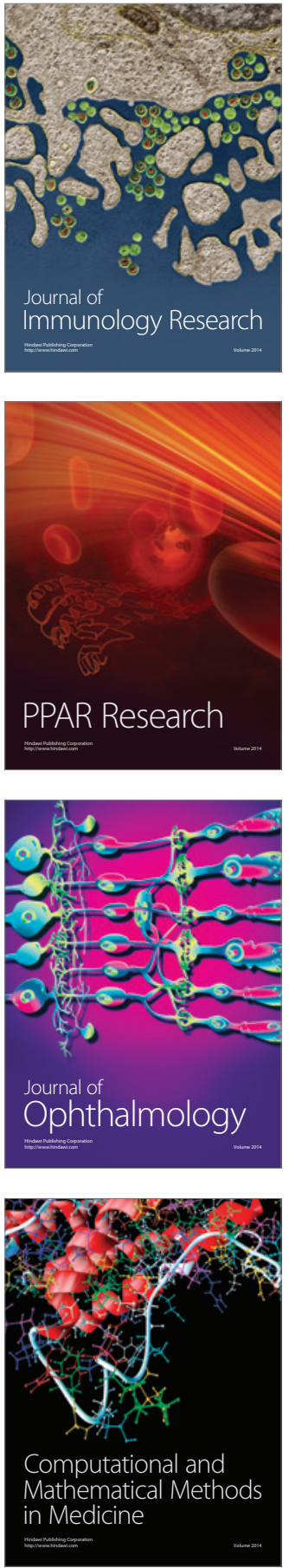

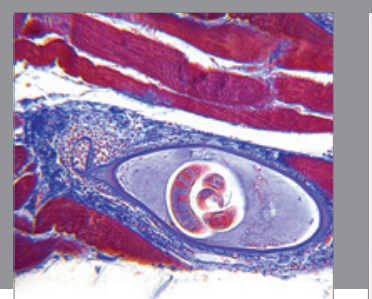

Gastroenterology Research and Practice

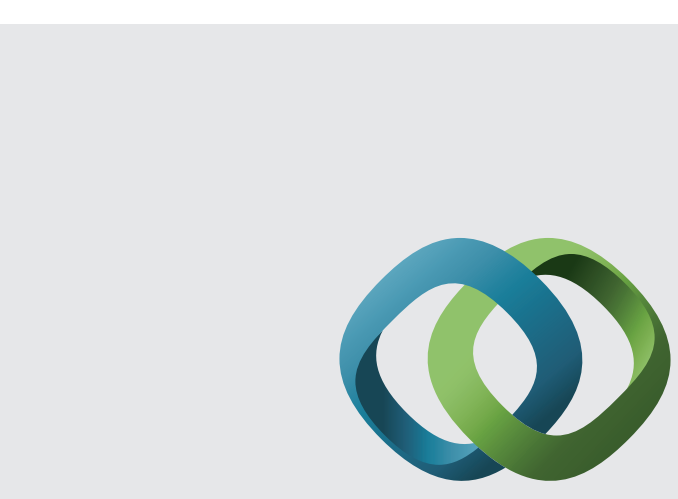

\section{Hindawi}

Submit your manuscripts at

http://www.hindawi.com
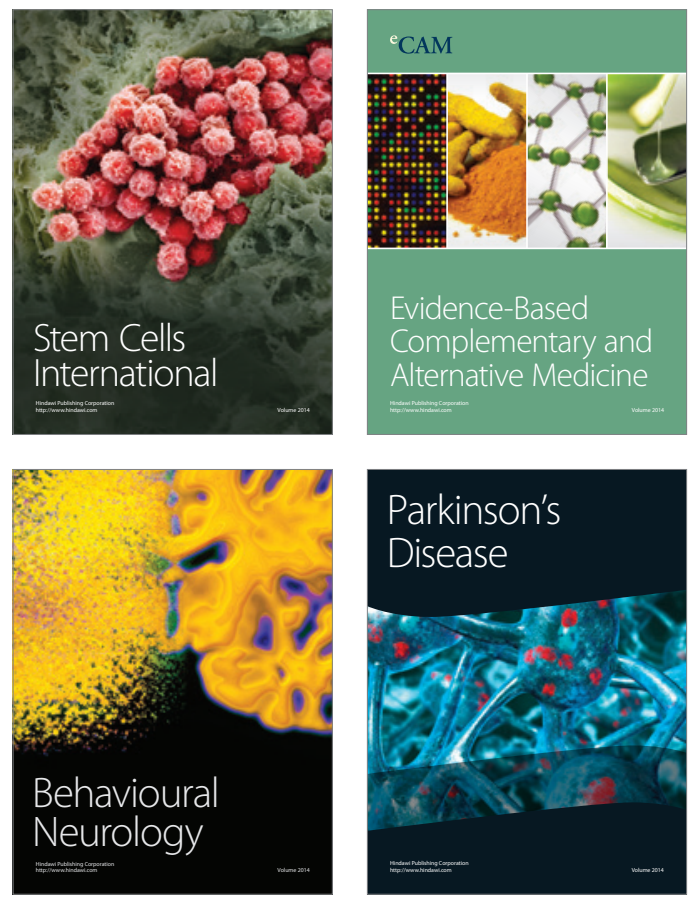
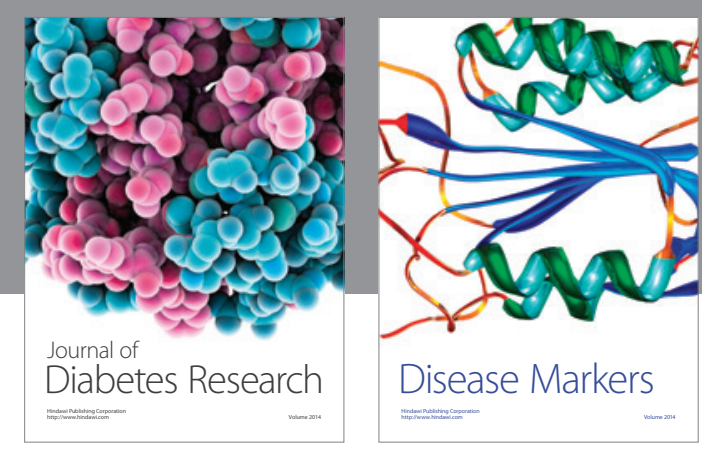

Disease Markers
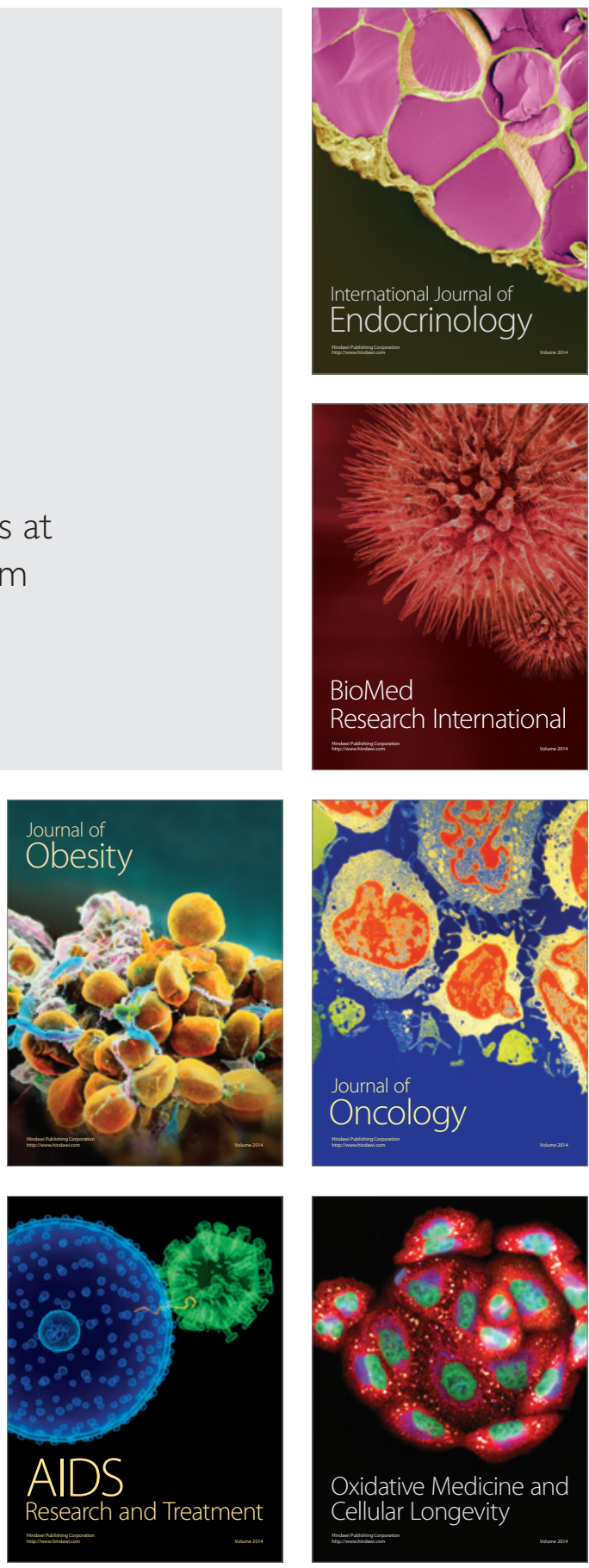